Fetal Diagnosis and Therapy
Fetal Diagn Ther 2016;39:248-255

DOI: $10.1159 / 000440649$
Received: April 7, 2015

Accepted after revision: August 25, 2015

Published online: November 13, 2015

\title{
Fetal Stomach Position Predicts Neonatal Outcomes in Isolated Left-Sided Congenital Diaphragmatic Hernia
}

\author{
Amaya M. Basta ${ }^{a}$ Leslie A. Lusk ${ }^{b}$ Roberta L. Keller ${ }^{b, c}$ Roy A. Fillyc, d \\ ${ }^{a}$ Department of Diagnostic Radiology, Oregon Health and Science University, Portland, Oreg., and bivision \\ of Neonatology, Department of Pediatrics, University of California San Francisco Benioff Children's Hospital, \\ CUniversity of California San Francisco Fetal Treatment Center, and ${ }^{\mathrm{d}}$ Department of Radiology and Biomedical \\ Imaging, University of California San Francisco Medical Center, San Francisco, Calif., USA
}

\section{Key Words}

Stomach · Fetal anomalies · Fetal imaging · Congenital diaphragmatic hernia $\cdot$ Lung hypoplasia $\cdot$ Neonatal outcome · Prenatal diagnosis · Perinatal mortality

\begin{abstract}
Introduction: We sought to determine the relationship between the degree of stomach herniation by antenatal sonography and neonatal outcomes in fetuses with isolated left-sided congenital diaphragmatic hernia (CDH). Materials and Methods: We retrospectively reviewed neonatal medical records and antenatal sonography of fetuses with isolated left CDH cared for at a single institution (2000-2012). Fetal stomach position was classified on sonography as follows: intra-abdominal, anterior left chest, mid-to-posterior left chest, or retrocardiac (right chest). Results: Ninety fetuses were included with $70 \%$ surviving to neonatal discharge. Stomach position was intra-abdominal in $14 \%(n=13)$, anterior left chest in 19\% ( $n=17)$, mid-to-posterior left chest in $41 \%(n=37)$, and retrocardiac in $26 \%(n=23)$. Increasingly abnormal stomach position was linearly associated with an increased odds of death (OR 4.8,95\% Cl 2.1-10.9), extracorporeal membrane oxygenation (ECMO; OR 5.6, 95\% Cl 1.916.7), nonprimary diaphragmatic repair (OR $2.7,95 \% \mathrm{Cl} 1.4-$
\end{abstract}

5.5), prolonged mechanical ventilation (OR $5.9,95 \% \mathrm{Cl} 2.3-$ 15.6), and prolonged respiratory support (OR $4.0,95 \% \mathrm{Cl}$ 1.6-9.9). All fetuses with intra-abdominal stomach position survived without substantial respiratory morbidity or need for ECMO. Discussion: Fetal stomach position is strongly associated with neonatal outcomes in isolated left $\mathrm{CDH}$. This objective tool may allow for accurate prognostication in a variety of clinical settings.

(c) 2015 S. Karger AG, Basel

\section{Introduction}

Congenital diaphragmatic hernia $(\mathrm{CDH})$ affects approximately 1 in 4,000 pregnancies and is predominantly left-sided [1]. Despite advances in antenatal diagnosis

Amaya M. Basta and Leslie A. Lusk contributed equally and are sharing the first authorship of this work. This work has been presented, in whole or in part, at the 6th International Conference of Neonatal and Childhood Pulmonary Vascular Disease in June 2013, the Society for Radiologists in Ultrasound Annual Meeting in October 2013, the Pacific Coast Pediatric Radiology Association Annual Meeting in July 2014, and the Society for Pediatric Radiology Annual Meeting in April 2015.

\section{KARGER}

E-Mail karger@karger.com www.karger.com/fdt (c) 2015 S. Karger AG, Basel

$1015-3837 / 15 / 0394-0248 \$ 39.50 / 0$
Amaya M. Basta, MD

Department of Diagnostic Radiology, Oregon Health and Science University 3181 SW Sam Jackson Park Road, DC7R

Portland, OR 97239 (USA)

E-Mail Basta@OHSU.edu 
and perinatal treatment, significant morbidity and mortality persist, primarily due to pulmonary hypoplasia [25]. The degree of pulmonary hypoplasia can be assessed antenatally by various imaging approaches, including determination of liver position (intra-abdominal vs. intrathoracic) and measurements of contralateral [lung-tohead ratio (LHR) or observed-to-expected LHR], or total, lung size [3,6-11]. However, clinical experience and published data suggest that there is variability in the assessment of these prognostic measurements, in particular LHR and liver position by sonography [7, 12-17]. Thus, a more reliable and reproducible prognostic indicator would be useful in the fetal assessment of left $\mathrm{CDH}$.

The consideration of fetal stomach position in left $\mathrm{CDH}$ is not a new concept $[2,5,7,8,10,12,18-25]$. Prior reports indicate that for isolated left $\mathrm{CDH}$, liver position is helpful in predicting the severity of the lesion, and herniation of the stomach into the left chest, particularly if located in the mid-to-posterior left chest, helps predict liver herniation. It is already established that intra-abdominal fetal stomach position is associated with a favorable prognosis; the presence of the stomach within the thorax during the fetal or neonatal period has been shown in multiple studies to correlate with adverse outcome. Specifically, survival ranges of $25-41$ versus $83-100 \%$ have been reported for the dichotomous classification of intrathoracic versus intra-abdominal stomach position, respectively, in left $\mathrm{CDH}$. Yet, antenatal stomach position has not been broadly applied as a predictor of neonatal outcome.

Recently, Kitano and colleagues [8,25] used multiple levels of progressively aberrant fetal stomach position to demonstrate that stomach herniation into the right chest conferred the highest likelihood of poor neonatal outcome. However, their proposed algorithm requires particular expertise in the fetal evaluation of left $\mathrm{CDH}$ : the determination of liver position and judgment as to the degree of abnormality of the herniated stomach $[12,25$, 26]. Cordier et al. [21] recently demonstrated that fetal stomach position was predictive of postnatal survival and the need for prosthetic patch repair of the diaphragm defect. However, to our knowledge, the relationship between fetal stomach position, neonatal extracorporeal membrane oxygenation (ECMO) requirement, and short-term respiratory morbidity has not yet been reported.

In our study, we employed an objective classification of stomach position (similar to that proposed by Cordier et al. [21]) and hypothesized that the degree of abnormality in stomach position on fetal sonography would be an accurate and reproducible indicator of important neonatal outcomes in isolated left $\mathrm{CDH}$, allowing for broad application as a useful predictor.

\section{Materials and Methods}

We conducted a retrospective cohort study of consecutive fetuses with left $\mathrm{CDH}$ evaluated at the University of California San Francisco (UCSF) Fetal Treatment Center who received neonatal care at the UCSF Benioff Children's Hospital from January 2000 to June 2012. Fetuses were excluded if a genetic syndrome, additional coexisting anomalies, or a Morgagni-type hernia was diagnosed, or if appropriate fetal images could not be obtained. Under institutional review board approval, fetal ultrasound examinations and medical records were reviewed (see below).

\section{Patient Management}

Infants were managed with a lung-protective ventilation strategy, as previously described $[27,28]$. ECMO was initiated if the patient had impending inadequate oxygen delivery despite optimal support. Surgical repair was performed following clinical stabilization, generally within the first week of life. Clinical decisions were not made based on fetal sonographic assessments of lung hypoplasia, such as LHR or liver position.

\section{Imaging Data}

A single radiologist (R.A.F.) blinded to neonatal outcomes reinterpreted each fetus' first formal fetal anatomy sonogram performed by the UCSF Department of Radiology. Gestational age at the time of this sonogram was recorded. Stomach position was determined while viewing the fetal thorax in the true axial plane at the level of the 4-chamber view of the heart. It was classified by increasingly abnormal position based on the degree of herniation into the thoracic cavity as follows: intra-abdominal (fig. 1), anterior left chest (defined as a portion of the fetal stomach contacting the anterior chest wall; fig. 2), mid-to-posterior left chest (defined as not contacting the anterior left chest wall but possibly contacting the posterior left chest wall; fig. 3), or retrocardiac (defined as at least a portion of the stomach located posterior to the left atrium of the heart within the right chest; fig. 4). As it was frequently difficult to determine if the stomach was located in the mid versus posterior left chest, we simplified the classification of stomach position by combining these positions into a single category. This classification system is similar to that recently and independently proposed by Cordier and colleagues $[20,21]$, with our retrocardiac category indicating the most severely displaced stomach. To assess the reproducibility of this classification, a subset of 25 cases were reread by the same radiologist (R.A.F.) at a 1-year interval as well as by a radiology trainee (A.M.B.).

Liver position (defined as intra-abdominal with absence of any liver in the thorax and intrathoracic when any portion of the liver was herniated into the chest) was gathered from fetal ultrasound reports and verified by the postnatal operative report when surgery was performed. LHR measurements were collected from ultrasound reports and only included if the measurement was taken between 20 and 29 weeks of gestational age. Subjects not scanned within this window did not contribute LHR data to this analysis. The technique consistently used at UCSF measures the LHR on a 
Fig. 1. Classification of fetal stomach position in patients with left CDH. a, b Intraabdominal stomach position. a Transaxial gray-scale sonographic image of the chest in a 31.4-week-old fetus. Bowel loops herniated into the left chest displace the heart (Ht) to the right. The stomach is not seen within the chest. b Evaluation of the fetal abdomen demonstrated normal intra-abdominal location of the stomach (St). Sp = Spine; LT = left; RT = right.

Fig. 2. Classification of fetal stomach position in patients with left CDH. Anterior left chest stomach position. Transaxial grayscale sonographic image of the chest in a 25.4-week-old fetus. Herniated stomach (St) contacts the anterior chest wall and lies adjacent to the left ventricle of the heart (Ht) within the left chest. $\mathrm{Sp}=$ Spine; $\mathrm{ANT}=$ anterior

Fig. 3. Classification of fetal stomach position in patients with left CDH. Spectrum of mid-to-posterior left chest stomach position. a Transaxial gray-scale sonographic image of the chest in a 32-week-old fetus. The obliquely oriented stomach (St) contacts neither the anterior nor posterior chest walls and remains entirely within the mid portion of the left chest. $\mathbf{b}$ Transverse gray-scale sonographic image of the chest in a 20.7-week-old fetus. Herniated stomach (St) contacts the posterior wall of the left chest. $\mathrm{Ht}=$ Heart; $\mathrm{Sp}=$ spine.
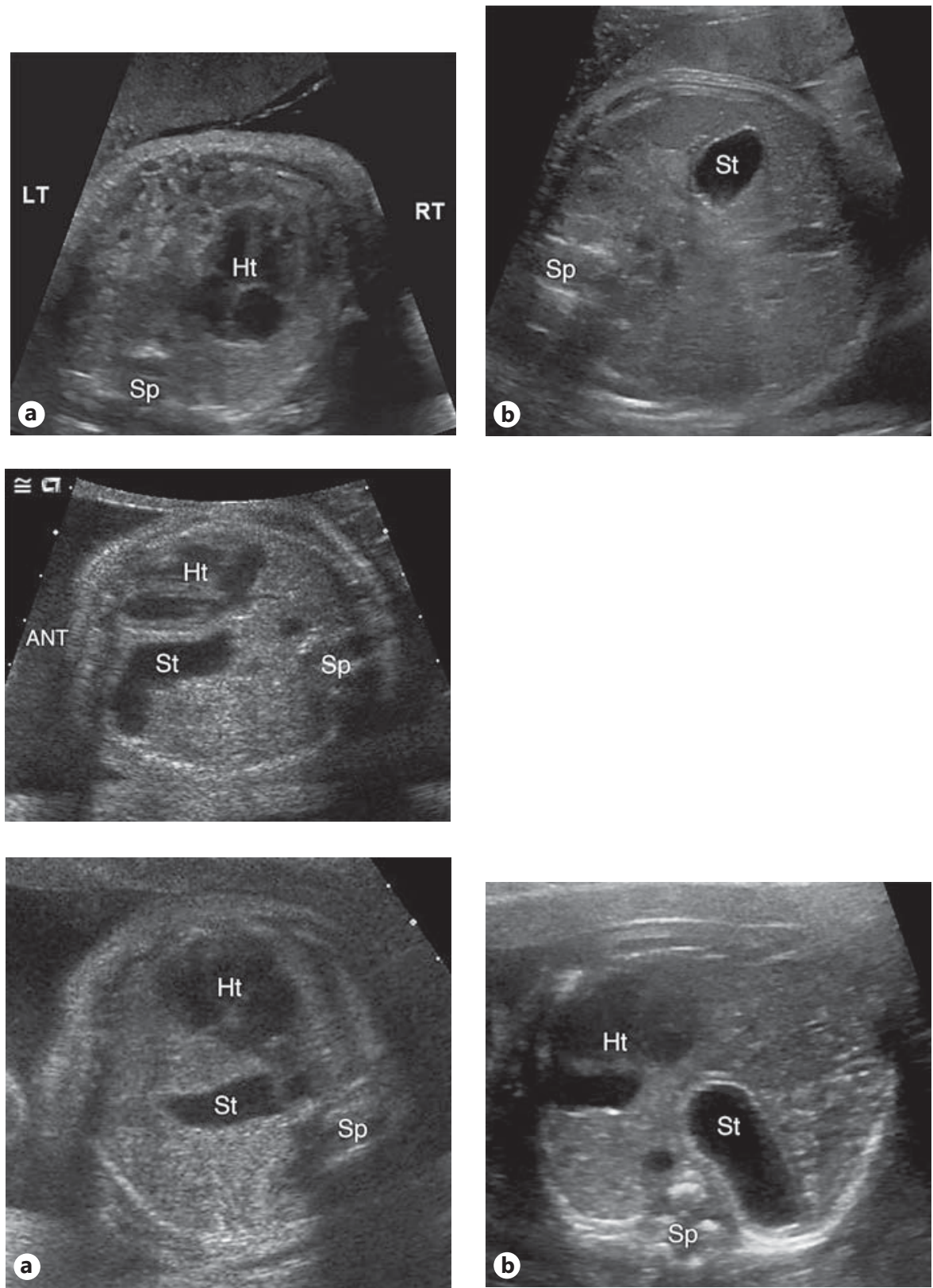

transaxial view of the fetal chest at the level of the 4-chamber view of the heart. This method uses the aorta and lateral rib as landmarks for the lateral measurement, which is multiplied by the orthogonal anterior-posterior diameter measured from the left cardiac atrium to the posterior rib; the resultant lung area is then divided by the head circumference.

\section{Clinical Data}

A single investigator blinded to the imaging data reviewed the medical records. The primary outcome of interest was death prior to hospital discharge. Secondary outcomes were the need for ECMO, nonprimary repair of the diaphragm defect (prosthetic patch or muscle flap), prolonged mechanical ventilation, and pro- longed respiratory support. Prolonged ventilation was defined as $>14$ days of age at the time of successful tracheal extubation, as we have previously shown that this categorization predicts later morbidity and is an important time point for resolution of pulmonary hypertension [27-29]. Prolonged respiratory support was defined as the need for any support (including nasal cannula oxygen or flow) at $\geq 56$ days of age or discharge on oxygen supplementation at $<56$ days based on the proposed definition of moderate-to-severe bronchopulmonary dysplasia for infants born at $>32$ weeks of gestational age in a National Institutes of Health workshop [30]. Consistent with this proposed definition, we have shown that infants with $\mathrm{CDH}$ who were discharged from their neonatal hospitalization on oxygen supplementation have a significant risk of 

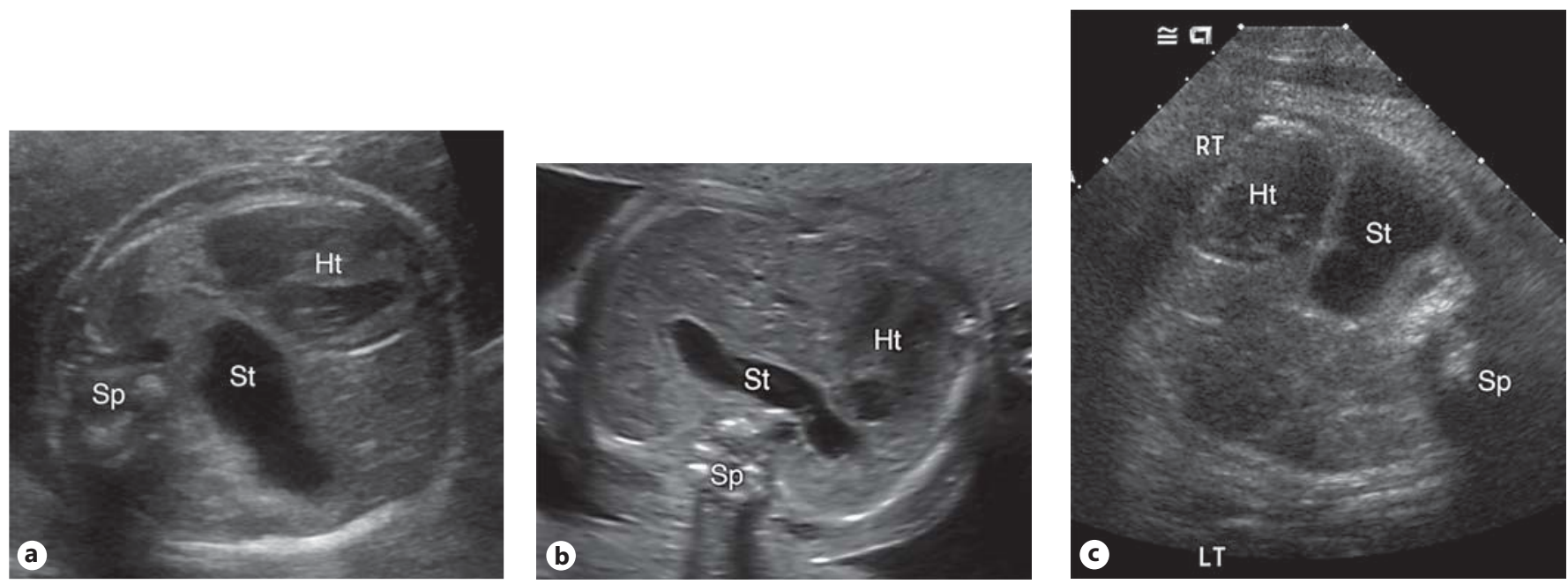

Fig. 4. Classification of fetal stomach position in patients with left $\mathrm{CDH}$. Spectrum of retrocardiac stomach position. $\mathbf{a}, \mathbf{b}$ Transaxial gray-scale sonographic images of the chest in 22.1-week-old (a) and 23.7-week-old (b) fetuses. In both, the stomach (St) is herniated across the midline, with a portion located behind the left atri- um of the heart (Ht). c Transaxial gray-scale sonographic image of the chest in a 41 -week-old fetus. The stomach (St) is entirely retrocardiac and contacts the right lateral chest wall. $\mathrm{Ht}=$ Heart; $\mathrm{Sp}=$ spine; $\mathrm{RT}=$ right; $\mathrm{LT}=$ left. later morbidity [29]. Additional clinical data collected were potential confounding variables, including maternal age, gestational age and birth weight, gender, mode of delivery, birth year, and prior fetal tracheal balloon occlusion [31].

\section{Statistical Analysis}

Bivariate analyses were performed using either Fisher's exact test or the Kruskal-Wallis test where appropriate. Statistically significant $(\mathrm{p}<0.05)$ potential confounding variables were included in the multivariate analysis, which was performed by logistic regression. We treated the degree of abnormal stomach position as a continuous linear variable in these models since the bivariate analysis suggested this relationship for the outcomes of interest (test of linear trend $\mathrm{p}<0.05$ for all outcomes). Odds ratios (ORs) and 95\% confidence intervals (CIs) for these estimates are presented. The inter- and intrarater reliability for the assessment of stomach position was analyzed using a linear weighted kappa statistic. We generated receiver operating characteristic (ROC) curves to assess the predictive accuracy of stomach position in comparison to both liver position and LHR (Stata version 12, Stata Corp., College Station, Tex., USA).

\section{Results}

\section{Subject Characteristics}

Between 2000 and 2012, a total of 129 fetuses with left $\mathrm{CDH}$ were referred to the UCSF Fetal Treatment Center for antenatal evaluation and received neonatal care in the Intensive Care Nursery at UCSF Benioff Children's Hos- pital. We could not retrieve sonographic images for 13 fetuses, who were therefore excluded. An additional 26 fetuses were excluded for the following reasons: Morgagni hernia $(\mathrm{n}=1)$, coexisting major congenital anomalies ( $\mathrm{n}=11$, including 7 with cardiac defects, 3 with pulmonary sequestration, and 1 with a head and neck teratoma), known congenital syndrome or multiple anomalies $(\mathrm{n}=$ 13), and family request for comfort care only at birth $(\mathrm{n}=1)$. Ninety fetuses met the inclusion criteria.

The characteristics of our study population are summarized in table 1 . Newborns were predominantly term or late preterm, with a slight male predominance. Fifteen fetuses (17\%) underwent tracheal balloon occlusion. The median gestational age at fetal sonography was 25.9 weeks (interquartile range 23.9-31.3). Stomach position was classified for all 90 fetuses and noted to be intra-abdominal in 13 (14\%), anterior left chest in 17 (19\%), mid-toposterior left chest in 37 (41\%), and retrocardiac in 23 (26\%). Fifty-two fetuses had an LHR measured between 20 and 29 weeks, and 88 had liver position documented.

Overall survival was 70\% (63/90). Thirteen newborns (14\%) required ECMO. Eighty newborns underwent surgical diaphragmatic hernia repair; of these, 56 (70\%) required nonprimary repair of the diaphragmatic defect. Fifty-three percent of those undergoing repair (42/80) required prolonged mechanical ventilation ( $>14$ days); 23 infants were never extubated. The mean age at successful 
tracheal extubation was $15 \pm 12$ days. For those discharged on room air, the mean age at discontinuation of all respiratory support was $17 \pm 12$ days, with a prolonged requirement for respiratory support ( $\geq 56$ days, or discharge on oxygen supplementation) in $33 \%(22 / 66)$ of infants.

\section{Relationship to Neonatal Outcomes}

Bivariate analysis demonstrated that progressively abnormal stomach position was significantly associated with an increased risk of death $(p<0.001)$, need for ECMO $(\mathrm{p}=0.005)$, nonprimary diaphragm repair $(\mathrm{p}<$ $0.001)$, prolonged mechanical ventilation $(\mathrm{p}<0.001)$, and prolonged respiratory support $(\mathrm{p}<0.001$; table 2$)$. All newborns with intra-abdominal fetal stomach position survived without ECMO support or prolonged ventilation or respiratory support. Twenty-seven of the 77 neonates $(35 \%)$ with intrathoracic fetal stomach position died prior to hospital discharge, with increased risk of death with progressively abnormal stomach position; only $39 \%(9 / 23)$ of newborns with retrocardiac stomach position survived. Similarly, while a minority of newborns in our study required ECMO, all of these patients had stomach herniation into the mid-to-posterior left chest or retrocardiac region. The majority of infants who underwent repair of the diaphragm had a nonprimary repair, which was progressively more common with a more aberrant stomach position; a significant proportion of infants with intra-abdominal stomach position and all infants with retrocardiac stomach position underwent nonprimary repair. Prolonged mechanical ventilation (>14 days) was also more common with more aberrant stomach position, as was prolonged respiratory support; two thirds of infants with a retrocardiac stomach position who survived to 56 days were still receiving support.

After adjusting for gestational age at birth, birth era, and fetal tracheal balloon occlusion (the only factors significantly associated with our outcomes in the bivariate analysis), progressively abnormal fetal stomach position continued to be associated with an increased odds of death (OR 4.8, 95\% CI 2.1-10.9, $\mathrm{p}<0.001$ ), need for ECMO (OR 5.6, 95\% CI 1.9-16.7, $\mathrm{p}=0.002$ ), nonprimary diaphragm repair (OR 2.7, 95\% CI 1.4-5.5, $\mathrm{p}=0.005$ ), prolonged mechanical ventilation (OR 5.9, 95\% CI 2.3$15.6, \mathrm{p}<0.001$ ), and prolonged respiratory support (OR $4.0,95 \%$ CI $1.6-9.9, \mathrm{p}=0.003)$.

\section{Diagnostic Assessment of Stomach Position}

Stomach position was a highly reproducible measurement, with an intrarater kappa statistic of 0.90 and an interrater kappa statistic of 0.97 . All misclassifications were
Table 1. Characteristics of patients with isolated left $\mathrm{CDH}$ born in 2000-2012 and treated at our institution

\begin{tabular}{lc}
\hline Maternal age, years & $31.3 \pm 6.0$ \\
Gestational age at birth, weeks & $37.2 \pm 2.8$ \\
$\quad<36$ weeks & $17(19)$ \\
Birth weight, g & $3,000 \pm 700$ \\
$\quad<2,500 \mathrm{~g}$ & $16(18)$ \\
Male gender & $53(59)$ \\
Cesarean section ${ }^{1}$ & $20(38)$ \\
Birth era & \\
$\quad 2000-2004$ & $27(30)$ \\
$2005-2008$ & $26(29)$ \\
$2009-2012$ & $37(41)$
\end{tabular}

Imaging data

Stomach position on first UCSF anatomic survey sonogram Abdominal

Anterior left chest

Mid-to-posterior left chest

Retrocardiac (right chest)

Median gestational age at time of sonogram, weeks 25.9 Interquartile range ${ }^{2}$

$23.9-31.3$

Fetal surgical data

Tracheal balloon occlusion

$15 / 90(17)$

Neonatal outcomes

Death

$27 / 90(30)$

ECMO

$13 / 90(14)$

Nonprimary diaphragm repair ${ }^{3}$

$56 / 80(70)$

Prolonged mechanical ventilation $(>14 \text { days })^{4} \quad 42 / 80(53)$

Prolonged respiratory support ( $\geq 56$ days $)^{5} \quad 22 / 66$ (33)

Figures are means \pm SD or number with percentages in parentheses, unless indicated otherwise.

${ }^{1}$ Data about mode of delivery were available for 53 patients.

${ }^{2}$ Gestational age by last menstrual period, or if unavailable, by ultrasound dating; total range 17.9-41 weeks.

${ }^{3}$ Excludes patients who died prior to surgical repair $(\mathrm{n}=80)$.

${ }^{4}$ Excludes patients who died prior to 14 days of age $(n=80)$.

${ }^{5}$ Of these, 7 patients were discharged home on oxygen prior to reaching 56 days of age. Age at discharge ranged from 29 to 43 days (mean $37.9 \pm 4.8$ ). Excludes patients who died prior to 56 days of age $(n=66)$.

by only one position, most commonly with the anterior versus mid-to-posterior left chest stomach positions. Only one misclassification between the mid-to-posterior left chest and retrocardiac position was seen. Areas under the ROC curves demonstrated good accuracy for stomach position as a predictor of all of the neonatal outcomes (table 3). Findings for liver position and LHR were similar. There were no statistically significant differences in predictive accuracy by the area under the ROC curves for stomach position compared to either liver position or LHR for any of the outcomes. 
Table 2. Fetal stomach position as a predictor of neonatal outcomes: bivariate analysis

\begin{tabular}{lllll}
\multicolumn{2}{l}{ Stomach position } \\
$\begin{array}{llll}\text { abdomen, } \\
\mathrm{n}\end{array}$ & $\begin{array}{l}\text { anterior left } \\
\text { chest, } \mathrm{n}\end{array}$ & $\begin{array}{l}\text { mid-to-posterior } \\
\text { left chest, } \mathrm{n}\end{array}$ & $\begin{array}{l}\text { retrocardiac } \\
\text { (right chest), } \mathrm{n}\end{array}$ & $\mathrm{p} \mathrm{value}^{*}$ \\
\end{tabular}

Neonatal outcomes

Death

ECMO

Nonprimary diaphragm repair ${ }^{1}$

$0 / 13(0 \%) \quad 0 / 17(0 \%)$

$12 / 37(32 \%)$

$14 / 23(61 \%)$
$8 / 23(35 \%)$

$<0.001$

$5 / 13(38 \%) \quad 9 / 17(53 \%)$

$5 / 37(14 \%)$

$17 / 17(100 \%)$

0.005

$0 / 13(0 \%) \quad 6 / 17(35 \%)$

$25 / 33(76 \%)$

$0 / 13(0 \%) \quad 3 / 16(19 \%)$

$13 / 28(46 \%)$

$15 / 16(94 \%)$

$<0.001$

Prolonged respiratory support ( $\geq 56$ days $)^{3}$

* p value refers to a Fisher's exact test of association.

${ }^{1}$ Excludes patients who died prior to surgical repair $(n=80) .{ }^{2}$ Excludes patients who died prior 14 days of age $(n=80) .{ }^{3}$ Of these, 7 patients were discharged home on oxygen prior to reaching 56 days of age. Age at discharge ranged from 29 to 43 days (mean $37.9 \pm$ 4.8). Excludes patients who died prior to 56 days of age $(n=66)$.

Table 3. Area under the ROC curve for stomach position, liver position, and LHR

\begin{tabular}{|c|c|c|c|c|c|c|c|c|}
\hline Outcome & \multicolumn{2}{|c|}{ Stomach position } & \multicolumn{3}{|c|}{ Liver position } & \multicolumn{3}{|l|}{ LHR } \\
\hline ECMO & 0.86 & $0.76-0.95$ & 0.74 & $0.59-0.88$ & 0.08 & 0.86 & $0.73-1.00$ & 0.92 \\
\hline Nonprimary repair & 0.74 & $0.62-0.86$ & 0.79 & $0.68-0.90$ & 0.38 & 0.65 & $0.47-0.83$ & 0.58 \\
\hline Prolonged ventilation & 0.88 & $0.80-0.95$ & 0.84 & $0.75-0.92$ & 0.24 & 0.80 & $0.70-0.91$ & 0.20 \\
\hline
\end{tabular}

${ }^{*}$ p value for the comparison of stomach position and liver position. ${ }^{\dagger} \mathrm{p}$ value for the comparison of stomach position and LHR.

\section{Discussion}

We hypothesized that the degree of abnormality in fetal stomach position on antenatal sonography would predict neonatal outcomes in isolated left $\mathrm{CDH}$. Our data strongly support the conclusion that stomach position is an accurate and reproducible predictor of neonatal prognosis. We have demonstrated a strong association between fetal stomach position and death, ECMO requirement, nonprimary repair of the diaphragm, and shortterm respiratory morbidity, with worse neonatal outcomes as the stomach progressively herniates from the abdomen to the anterior left chest, mid-to-posterior left chest, and finally to a retrocardiac (right chest) position.

In the current study, we utilize a classification of stomach position that should not require substantial expertise to determine. Importantly, the only technical require- ment is that the classification of stomach position be undertaken on a true axial sonogram of the fetal thorax. In support of this, we demonstrated very high intra- and interrater agreement. Finally, stomach position was predictive of all of the neonatal outcomes we evaluated, even though we imposed no restriction on the gestational age at sonography, making this measurement even more accessible than other alternatives $[7,17]$.

Unlike the methodology proposed by Kitano and colleagues $[8,25]$, our classification does not require the assessment of liver herniation, which is difficult to accurately determine on fetal ultrasound, even with experienced operators $[8,12,15,25]$. It has already been established that for isolated left $\mathrm{CDH}$, fetal liver position is predictive of the severity of the hernia, and stomach position helps predict liver position $[7,8,10,12,20]$; measurement of both further complicates the assessment without prognostic benefit. 
Our results complement the recent work of Cordier and colleagues $[20,21]$ who reported that fetal stomach position on ultrasound predicted not only the extent of liver herniation on fetal MRI but also postnatal survival and need for prosthetic patch repair. We similarly demonstrated high inter- and intraobserver reliability, and our estimates of the magnitude of effect of stomach position on survival and repair type are similar, over a broad range of gestational ages. Our work expands on Cordier's, however, as we evaluated additional important neonatal outcomes. We also compared the accuracy of stomach position for these neonatal outcomes to LHR and liver position, demonstrating equivalence of stomach position to these established predictors. Together, these observations confirm that stomach position performs across varied patient populations and centers.

These findings are clinically relevant because they show that the very simple observation of fetal stomach position is highly reproducible and predictive of multiple neonatal outcomes in isolated left $\mathrm{CDH}$; however, our study has several potential limitations. We performed our investigation at a single tertiary care facility, but the very high interrater agreement (kappa statistic of 0.97 ) adds credibility to the generalizability of our results in less experienced centers. In addition, although this was a retrospective study, neonatal outcomes were masked to those interpreting the ultrasounds, decreasing the risk of bias in these interpretations. Finally, although neonatology practices have evolved at our institution over the course of the 12 -year study period, we adjusted our results based on the patients' era of birth to minimize these effects on our estimates of the impact of stomach position.

An additional question may be raised over the persistence of this predictor during the course of gestation for an individual fetus. We categorized the fetal stomach po- sition on the patient's first formal sonogram, and the included studies were obtained over a range of gestational ages. However, we did not longitudinally assess for changes in fetal stomach position over the course of gestation since we designed this study to assess the utility of an initial observation in the evaluation of fetal CDH. Potential future lines of research could establish the persistence of fetal stomach position during the course of gestation for an individual fetus. Furthermore, these observations should be further substantiated by a prospective investigation of the predictive value of fetal stomach position in clinical practice.

In conclusion, we have demonstrated that the straightforward observation of fetal stomach position on sonography is an accurate predictor of neonatal prognosis in isolated left $\mathrm{CDH}$, and more abnormal fetal stomach position is associated with worsening clinical outcomes. The ease and reproducibility of this prognostic observation and its potential applicability over a wide range of gestational ages may allow for broad application in a variety of clinical settings.

\section{Acknowledgements}

Amaya M. Basta was supported by the National Institute of Biomedical Imaging and Bioengineering (T32 training grant EB001631) during the academic year 2012-2013. Leslie A. Lusk was supported by the National Institute of Child Health and Human Development (T32 HD-007162).

\section{Disclosure Statement}

None of the authors have any relevant commercial interests to disclose.

\section{References}

1 Yang W, Carmichael SL, Harris JA, Shaw GM: Epidemiologic characteristics of congenital diaphragmatic hernia among 2.5 million California births, 1989-1997. Birth Defects Res A Clin Mol Teratol 2006;76:170-174.

-2 Dommergues M, Louis-Sylvestre C, Mandelbrot L, Oury JF, Herlicoviez M, Body G, Gamerre M, Dumez Y: Congenital diaphragmatic hernia: can prenatal ultrasonography predict outcome? Am J Obstet Gynecol 1996; 174:1377-1381.
3 Jani J, Nicolaides KH, Keller RL, Benachi A, Peralta CF, Favre R, Moreno O, Tibboel D, Lipitz S, Eggink A, Vaast P, Allegaert K, Harrison $\mathrm{M}$, Deprest J: Observed to expected lung area to head circumference ratio in the prediction of survival in fetuses with isolated diaphragmatic hernia. Ultrasound Obstet Gynecol 2007;30:67-71.

4 Knox E, Lissauer D, Khan K, Kilby M: Prenatal detection of pulmonary hypoplasia in fetuses with congenital diaphragmatic hernia: a systematic review and meta-analysis of diagnostic studies. J Matern Fetal Neonatal Med 2010;23:579-588.

\footnotetext{
5 Mann PC, Morriss FH Jr, Klein JM: Prediction of survival in infants with congenital diaphragmatic hernia based on stomach position, surgical timing, and oxygenation index. Am J Perinatol 2012;29:383-390.

-6 Done E, Debeer A, Gucciardo L, Van Mieghem T, Lewi P, Devlieger R, De Catte L, Lewi L, Allegaert K, Deprest J: Prediction of neonatal respiratory function and pulmonary hypertension in fetuses with isolated congenital diaphragmatic hernia in the fetal endoscopic tracheal occlusion era: a singlecenter study. Fetal Diagn Ther 2015;37:2432.
} 
7 Hedrick HL, Danzer E, Merchant A, Bebbington MW, Zhao H, Flake AW, Johnson MP, Liechty KW, Howell LJ, Wilson RD, Adzick NS: Liver position and lung-to-head ratio for prediction of extracorporeal membrane oxygenation and survival in isolated left congenital diaphragmatic hernia. Am J Obstet Gynecol 2007;197:422.e1-e4.

8 Kitano Y, Nakagawa S, Kuroda T, Honna T, Itoh Y, Nakamura T, Morikawa N, Shimizu N, Kashima K, Hayashi S, Sago H: Liver position in fetal congenital diaphragmatic hernia retains a prognostic value in the era of lungprotective strategy. J Pediatr Surg 2005;40: $1827-1832$.

-9 Lipshutz GS, Albanese CT, Feldstein VA, Jennings RW, Housley HT, Beech R, Farrell JA, Harrison MR: Prospective analysis of lung-tohead ratio predicts survival for patients with prenatally diagnosed congenital diaphragmatic hernia. J Pediatr Surg 1997;32:16341636.

10 Metkus AP, Filly RA, Stringer MD, Harrison MR, Adzick NS: Sonographic predictors of survival in fetal diaphragmatic hernia. J Pediatr Surg 1996;31:148-151; discussion 151152.

11 Ruano R, Takashi E, da Silva MM, Campos JA, Tannuri U, Zugaib M: Prediction and probability of neonatal outcome in isolated congenital diaphragmatic hernia using multiple ultrasound parameters. Ultrasound $\mathrm{Ob}$ stet Gynecol 2012;39:42-49.

-12 Bootstaylor BS, Filly RA, Harrison MR, Adzick NS: Prenatal sonographic predictors of liver herniation in congenital diaphragmatic hernia. J Ultrasound Med 1995;14:515-520.

-13 Cruz-Martinez R, Figueras F, Moreno-Alvarez O, Martinez JM, Gomez O, HernandezAndrade E, Gratacos E: Learning curve for lung area to head circumference ratio measurement in fetuses with congenital diaphragmatic hernia. Ultrasound Obstet Gynecol 2010;36:32-36.
4 Keller RL, Glidden DV, Paek BW, Goldstein RB, Feldstein VA, Callen PW, Filly RA, Albanese CT: The lung-to-head ratio and fetoscopic temporary tracheal occlusion: prediction of survival in severe left congenital diaphragmatic hernia. Ultrasound Obstet Gynecol 2003;21:244-249.

15 Richards DS, Kays DM: Fetal umbilical vein deviation in congenital diaphragmatic hernia. J Ultrasound Med 2013;32:263-268.

16 Taipale P, Ammala M, Salonen R, Hiilesmaa $\mathrm{V}$ : Learning curve in ultrasonographic screening for selected fetal structural anomalies in early pregnancy. Obstet Gynecol 2003;101: 273-278.

17 Yang SH, Nobuhara KK, Keller RL, Ball RH, Goldstein RB, Feldstein VA, Callen PW, Filly RA, Farmer DL, Harrison MR, Lee H: Reliability of the lung-to-head ratio as a predictor of outcome in fetuses with isolated left congenital diaphragmatic hernia at gestation outside 24-26 weeks. Am J Obstet Gynecol 2007; 197:30.e1-e7.

18 Aiello H, Meller C, Vázquez L, Otaño L: Stomach in contact with the bladder: a sonographic sign of left congenital diaphragmatic hernia. Fetal Diagn Ther, Epub ahead of print.

19 Burge DM, Atwell JD, Freeman NV: Could the stomach site help predict outcome in babies with left sided congenital diaphragmatic hernia diagnosed antenatally? J Pediatr Surg 1989;24:567-569.

20 Cordier AG, Cannie MM, Guilbaud L, De Laveaucoupet J, Martinovic J, Nowakowska D, Milejska-Lewandowska M, Rodo C, Viaris de Lesegno B, Votino C, Senat MV, Jani JC, Benachi A: Stomach position versus liver-to thoracic volume ratio in left-sided congenital diaphragmatic hernia. J Matern Fetal Neonatal Med 2015;28:190-195.

21 Cordier AG, Jani JC, Cannie MM, Rodo C, Fabietti I, Persico N, Saada J, Carreras E, Senat MV, Benachi A: Stomach position in the prediction of survival in left-sided congenital diaphragmatic hernia with or without fetoscopic endoluminal tracheal occlusion. Ultrasound Obstet Gynecol 2015;46:155-161.

-22 Datin-Dorriere V, Rouzies S, Taupin P, Walter-Nicolet E, Benachi A, Sonigo P, Mitanchez $D$ : Prenatal prognosis in isolated congenital diaphragmatic hernia. Am J Obstet Gynecol 2008;198:80.e1-e5.
23 Goodfellow T, Hyde I, Burge DM, Freeman NV: Congenital diaphragmatic hernia: the prognostic significance of the site of the stomach. Br J Radiol 1987;60:993-995.

24 Hatch EI Jr, Kendall J, Blumhagen J: Stomach position as an in utero predictor of neonatal outcome in left-sided diaphragmatic hernia. J Pediatr Surg 1992;27:778-779.

25 Kitano Y, Okuyama H, Saito M, Usui N, Morikawa N, Masumoto K, Takayasu H, Nakamura T, Ishikawa H, Kawataki M, Hayashi S, Inamura N, Nose K, Sago H: Re-evaluation of stomach position as a simple prognostic factor in fetal left congenital diaphragmatic hernia: a multicenter survey in Japan. Ultrasound Obstet Gynecol 2011;37:277-282.

26 Hubbard AM, Crombleholme TM, Adzick NS, Coleman BG, Howell LJ, Meyer JS, Flake AW: Prenatal MRI evaluation of congenital diaphragmatic hernia. Am J Perinatol 1999; 16:407-413.

27 Keller RL, Tacy TA, Hendricks-Munoz K, Xu J, Moon-Grady AJ, Neuhaus J, Moore P, Nobuhara KK, Hawgood S, Fineman JR: Congenital diaphragmatic hernia: endothelin-1, pulmonary hypertension, and disease severity. Am J Respir Crit Care Med 2010;182:555561.

28 Lusk LA, Wai KC, Moon-Grady AJ, Steurer MA, Keller RL: Persistence of pulmonary hypertension by echocardiography predicts short-term outcomes in congenital diaphragmatic hernia. J Pediatr 2015;166:251-256.e1.

29 Keller RL, Jancelewicz T, Vu L, Bratton B, Golden S, Piecuch R, Nobuhara K: Perinatal anatomic and physiologic factors predict neurodevelopmental (ND) disability in congenital diaphragmatic hernia (CDH). E-PAS 2008; 635848:12.

30 Jobe AH, Bancalari E: Bronchopulmonary dysplasia. Am J Respir Crit Care Med 2001; 163:1723-1729.

31 Harrison MR, Albanese CT, Hawgood SB, Farmer DL, Farrell JA, Sandberg PL, Filly RA: Fetoscopic temporary tracheal occlusion by means of detachable balloon for congenital diaphragmatic hernia. Am J Obstet Gynecol 2001;185:730-733. 